\title{
Costovertebral angle as a novel tool for predicting the thoracic complication risk following percutaneous nephrolithotomy requiring supracostal access
}

\begin{abstract}
Ahmet Güzel1; Taylan Oksay²; Sefa Alperen Ozturk²; Arap Sedat Soyupek²; Alper Ozorak², Alim Kosar ${ }^{2}$

${ }^{1}$ Department of Urology, Aydın State Hospital, Aydın, Turkey; ${ }^{2}$ Department of Urology, Faculty of Medicine, Suleyman Demirel University, Isparta, Turkey
\end{abstract}

Cite as: Guzel A, Oksay T, Ozturk SA, et al. Costovertebral angle as a novel tool for predicting the thoracic complication risk following percutaneous nephrolithotomy requiring supracostal access. Can Urol Assoc J 2021 May 11; Epub ahead of print.

http://dx.doi.org/10.5489/cuaj.7114

Published online May 11, 2021

Correspondence: Dr. Ahmet Güzel, Department of Urology, Aydın State Hospital, Aydin, Turkey; drahmetguzel@yahoo.com

$* * *$

\section{Abstract}

Introduction: The objective of this study was to determine whether the costovertebral angle (CVA) and other factors can predict the risk of thoracic complications following percutaneous nephrolithotomy (PCNL).

Methods: The data of patients who underwent prone PCNL with supracostal access at Suleyman Demirel University Hospital between January 2015 and December 2019 were retrospectively reviewed. Patients' demographics information (age, sex, body mass index [BMI], stone size, and stone location), operative data (supracostal access site, renal puncture site, and laterality), and postoperative thoracic complications (pleural injury) were evaluated. The CVA was measured on preoperative posteroanterior chest X-ray images. The mean CVA of patients with and without thoracic complications was evaluated.

Results: A total of 89 patients (mean age $46.12 \pm 15.66$ years; 59 men and 30 women) with supracostal access were included in the study. Thoracic complications occurred in 17 (19.1\%) patients. Nine (52.9\%) hemothorax cases, five (29.4\%) pneumothorax cases, and three $(17.7 \%)$ urinothorax cases were detected. There was a statistically significant difference in the complication rate compared to the percutaneous access site $\left(10^{\text {th }}-11^{\text {th }}\right.$ supracostal vs. $11^{\text {th }}-12^{\text {th }}$ supracostal) $(\mathrm{p}=0.004)$. The mean CVA was significantly lower in patients with complications $(45.47 \pm 3.59)$ than in those without complications $(53.26 \pm 5.98)(\mathrm{p}=0.000)$. No association was found $(p>0.05)$ with age, sex, BMI, laterality, stone surface area, and access site among patients with and without thoracic complications. 
Conclusions: Preoperative CVA can be an effective tool in predicting the risk of postoperative thoracic complications.

\section{Introduction}

Percutaneous nephrolithotomy (PCNL) is a minimally invasive treatment technique that is recommended as the first step in guidelines for the treatment of kidney stones $>20 \mathrm{~mm} .{ }^{1,2}$ Developments in this technique and technology, which are reflected in its becoming a minimally invasive surgery, has also significantly increased the complication rates. ${ }^{3}$ The most frequent complications of PCNL are fever (21\%-32.1\%), bleeding requiring blood transfusion $(11.2 \%-17.5 \%)$, and extravasation (7.2\%). ${ }^{4}$ However, injuries to adjacent organs have also been reported as complications of PCNL, with pleural injury $(0 \%-3.1 \%)$ reported as the most common adjacent organ injury. ${ }^{4}$ Hydrothorax, pneumothorax, and hydropneumothorax usually occur following pleural injury during PCNL (especially at the access and dilatation stage), and approximately $64 \%$ of patients with pleural injury require chest tube drainage.$^{5-7}$ Some clinical symptoms (difficulty with ventilation, shortness of breath, and fever), physical examination findings (decreased breath sounds), and radiographic findings of pleural injury on chest radiographs have been observed in patients with thoracic complications in the acute postoperative period of PCNL. ${ }^{8}$

In the literature, tables, parameters, or nomograms are used to predict the possibility of stone clearance. ${ }^{9}$ However, there are no known parameters that can estimate the risk of complications. A study showed that the overall complication rate was $16.3 \%$ for supracostal access and $4.5 \%$ for subcostal access, regardless of the percutaneous approach. ${ }^{10}$ If the thoracic complication rates are compared, only $<0.5 \%$ of cases punctured below the 12 th rib, $3 \%-15 \%$ of cases punctured above the 12 th rib, and $10 \%-100 \%$ of cases punctured above the 11 th rib developed hydro-/pneumothorax. ${ }^{10,11}$ In addition, the role of other factors contributing to complications remains unknown. ${ }^{11}$ This retrospective study aimed to evaluate the role of the costovertebral angle (CVA) and other factors in predicting the risk of thoracic complications following PCNL.

\section{Methods}

This study was approved by the Suleyman Demirel University Clinical Research Ethics Committee (approval number: 14/198). The procedures used in this study adhere to the tenets of the Declaration of Helsinki. A total of 1021 patients with nephrolithiasis (645 men, 376 women; mean age, $44.98 \pm 16.35$ years, range $2-85$ years) underwent prone PCNL between January 2015 and December 2019. Of these patients, 89 underwent PCNL with supracostal access, performed by two experienced urologists. In these patients, preoperative, operative, postoperative, and radiological findings were analyzed and compared retrospectively. The patients' demographic information (age, sex, body mass index [BMI], stone size, and stone location), operative data (supracostal access site, renal puncture site, and laterality), and presence of postoperative thoracic complications (pleural injury) were obtained from the 
patients' records. The largest axial and coronal diameters were measured separately for the stone size. In patients with multiple stones, stone sizes were calculated separately and the sum of the values was recorded. Staghorn was defined for stones that filled $\geq 80 \%$ of the entire pelvicalyceal system. ${ }^{12} \mathrm{CVA}$ was defined as the angle of the costovertebral joint between the line passing through the middle of the vertebral column and the line passing through the middle of the $12^{\text {th }}$ rib measured on preoperative standing posteroanterior chest X-ray (CXR) on inspiration (Fig. 1). The CVA of all patients with and without thoracic complications was recorded. All patients who had supracostal access were evaluated using CXR to exclude pneumothorax or hydrothorax immediately after surgery. Pneumothorax was diagnosed based on the displacement of the pleural line in postoperative CXR. ${ }^{13}$ However, hydro-

/hydropneumothorax was diagnosed if the costophrenic angle and/or the diaphragm were not visible due to fluid density, as detected by postoperative CXR ${ }^{14}$ If hydrothorax was detected, diagnostic thoracentesis was performed to distinguish hemothorax from urinothorax. Patients with thoracic complications and respiratory distress underwent tube thoracostomy, which was then removed when sufficient lung re-expansion was achieved. Asymptomatic patients with thoracic complications were treated conservatively, and no surgical intervention was required as they were clinically stable. Patients who underwent surgery for the ipsilateral kidney, those who underwent PCNL with subcostal access and multiple access points, those with preoperative placement of a nephrostomy tract, those without preoperative posteroanterior CXR images, and pediatric patients were excluded.

\section{Standard PCNL technique}

Under general anesthesia, a suitable calyx was selected for puncture after the contrast agent was injected through the ureteric catheter. One of two methods of percutaneous renal access, namely, triangulation technique or "eye of the needle" technique, was selected. ${ }^{15} \mathrm{In}$ accordance with published information, ${ }^{16}$ access was established under C-arm fluoroscopy during full expiration using an 18-gauge needle while the patient was in the prone position, and the needle was advanced just above the upper limit of the rib to avoid damage to the intercostal vessels. The tract was dilated up to 30 Fr using Amplatz dilatators (Cook Inc., USA). Fragmentation of the stone burden was performed using a pneumatic lithotripter (Vibrolith ${ }^{\circledR}$, Elmed, Ankara, Turkey). In all cases, 14-Fr nephrostomy catheters (Devon Innovations, UK) were inserted into the renal pelvis or related calyx at the end of the operation. As a last step, nephrostogram was performed to ensure the location of the nephrostomy tube.

\section{Statistical analysis}

For descriptive statistics, frequency tables and cross tables were constructed. For comparisons, data were categorized and the chi square $(\chi 2)$ test was used. Chi-squared automatic interaction detector (CHAID) analysis, which is a decision tree method, was performed to investigate the effects of all independent variables used in the analysis on complications. IBM SPSS Statistics for Windows version 25 (IBM Corp., Armonk, NY) was used for data analysis, and the level of significance was set at 0.05 . 


\section{Results}

Patients' demographics and stone characteristics are shown in Table 1. Among the patients who underwent PCNL, 89 (8.7\%) underwent PCNL with supracostal access. Thoracic complications occurred in 17 of these patients (19.1\%). Although supracostal access was established above the 12th rib in 78 cases, it was established above the 11th rib in 11 cases. With regard to complications, nine (52.9\%) hemothorax cases, five $(29.4 \%)$ pneumothorax cases, and three (17.7\%) urinothorax cases were detected. Twelve patients with respiratory distress (Clavien grade IIIA) were treated via intercostal tube drainage under local anesthesia, and the tube was removed when a sufficient degree of lungs re-expansion was achieved. In contrast, five asymptomatic patients with thoracic complications (Clavien grade I) were treated conservatively, and no surgical intervention was required as they were clinically stable. The length of hospital stay ranged from 6 to 20 days in 17 patients with thoracic complications. The median length of hospital stay was $54 \mathrm{~h}$ (interquartile range, 51-58). All patients without complications were discharged on the second postoperative day.

Factors associated with thoracic complications are shown in Table 2. A statistical difference was found in complication rates up to the percutaneous access point $\left(10^{\text {th }}-11^{\text {th }}\right.$ supracostal versus $11^{\text {th }}-12^{\text {th }}$ supracostal $)(p=0.004)$. Higher thoracic complications rates were noted in cases with access via the $10^{\text {th }}-11^{\text {th }}$ intercostal space $(54.5 \%, 6 / 11)$ than in cases with access via the $11^{\text {th }}-12^{\text {th }}$ intercostal space $(14.1 \%, 11 / 78)(\mathrm{p}=0.004)$. The mean CVA was significantly lower in patients with complications $(45.47 \pm 3.59)$ than in those without complications $(53.26 \pm 5.98)(\mathrm{p}=0.000)$. Moreover, cases with a CVA range of $40^{\circ}-45^{\circ}$ $(60.0 \%, 9 / 15)$ experienced thoracic complications, which was significantly higher $(\mathrm{p}=0.000)$ than in cases with CVA of $46^{\circ}-51^{\circ}(25.0 \%, 8 / 32)$ and CVA of $>51^{\circ}(0.0 \%, 0 / 42)$.

Significantly higher thoracic complication rates $(50.0 \%, 3 / 6 ; 46.7 \%, 7 / 15)$ were noted in patients with midpolar and upper pole stone locations than in those with other stone locations $(5.9 \%, 1 / 17 ; 11.8 \%, 6 / 51)(\mathrm{p}=0.002)$. No association was found $(\mathrm{p}>0.05)$ with age $(46.12 \pm$ 16.30 vs. $46.12 \pm 15.63)$, sex (4 [13.3]/26 [86.7] vs. 13 [22.0]/46 [78]), BMI (26.99 \pm 4.87 vs. $25.35 \pm 524)$, laterality $(10[20.0] / 40[80.0]$ vs. 7 [17.9] vs. 32 [82.1]) stone size (axial, 23.18 \pm 8.87 vs. $24.41 \pm 8.96$; coronal, $18.26 \pm 7.48$ vs. $18.12 \pm 9.10$ ), and renal puncture site between patients with and without thoracic complications.

The results of the CHAID analysis, with estimates of $10.1 \%$ risk and $89.9 \%$ confidence, are shown in Figure 2. All 11 independent variables were included in the decision tree, and their effects on complication development were analyzed. The variable that had the greatest effect on complication development was CVA $\left(\chi^{2}=26.875 \mathrm{df}=2, \mathrm{p}=0.000\right)$. The model divided all angle groups into separate nodes, and the development of complications varied in all angle groups. According to the model, cases with the highest risk of complications were those with CVA of $40^{\circ}-45^{\circ}(60.0 \%)$. Patients with CVA of $46^{\circ}-51^{\circ}$ followed those with CVA of $40^{\circ}-45^{\circ}$, and the risk of complications was $25.0 \%$. Patients with CVA of $>51^{\circ}$ were not at risk of developing complications. When the CVA was $46^{\circ}-51^{\circ}$, the model showed the supracostal access site as a second factor. When the CVA was $46^{\circ}-51^{\circ}$ and the supracostal access site was the $10^{\text {th }}-11^{\text {th }}$ intercostal space, all patients developed 
complications, and when the supracostal access site was the $11^{\text {th }}-12^{\text {th }}$ intercostal space, $11.1 \%$ of the patients developed complications.

\section{Discussion}

In this study, we revealed for the first time a relationship between the CVA and the risk of thoracic complications. However, we showed that the risk of thoracic complications decreases as the CVA increases.

The actual incidence of pleural injury remains unknown because in most cases it is not noticeable as the injury is clinically insignificant. ${ }^{14,17}$ The majority of pleural injuries heal spontaneously over time. Sofer et al. evaluated non-contrast computed tomography (CT) findings of 100 patients who underwent PCNL and found no correlation between those diagnosed with pleural effusion with $\mathrm{CT}$ and clinical pleural effusions. ${ }^{17} \mathrm{CXR}$ is the first-line imaging method recommended for the detection of thoracic complications. Therefore, CXR was performed to identify thoracic complications in the postoperative period in patients with supracostal access, regardless of the presence or absence of clinical symptoms (e.g., difficulty in ventilation and shortness of breath) and physical examination findings. ${ }^{8,13}$

Anatomically, the parietal pleura crosses the middle of the $12^{\text {th }}$ rib posteriorly and the $11^{\text {th }}$ rib at the posterior axillary line. ${ }^{18} \mathrm{~A}$ safe zone is present on the lateral side of the intersection between the $11^{\text {th }}$ intercostal space and the middle scapular line, which minimizes the risk of pleural injury. ${ }^{18}$ Therefore, due to the fact that we established supracostal access by puncturing the skin and subcutaneous tissues during expiration and the renal parenchyma during inspiration from the safe area described above, we believe that the risk of thoracic complications is reduced and that our supracostal access is as safe as infracostal access. In all cases, we established PCNL intercostal access by puncturing the skin and subcutaneous tissue during expiration and the renal parenchyma during inspiration. Nevertheless, pleural complications occurred in $19.1 \%$ of the patients with supracostal access. The incidence of thoracic complications in patients with supracostal access was similar to that reported in the literature. ${ }^{10,19,20}$ However, the thoracic complication rate was higher in cases with $10^{\text {th }}-11^{\text {th }}$ intercostal access than in those with $11^{\text {th }}-12^{\text {th }}$ intercostal access and was similar to that reported by Munver et al. ${ }^{10}$ and Sinha et al. ${ }^{20}$

In our opinion, the higher thoracic complication rate in the $10^{\text {th }}-11^{\text {th }}$ intercostal access could be attributed to the anatomical course of the parietal pleura and diaphragm in the thorax, considering that even if the puncture was performed during expiration, the parietal pleura and diaphragm may come in the path of the needle. However, in the prone position, the lung may fill the posterior costodiaphragmatic recess even below the $12^{\text {th }}$ rib. ${ }^{21}$ Therefore, PCNL carries a risk of pleural complications, and understandably, the risk increases as the supracostal access site is higher. For this reason, we thought that CVA could be important in predicting the risk of thoracic complications.

To the best of our knowledge, no study has examined the relationship between CVA and thoracic complications in PCNL. The mean CVA of patients with thoracic complications was significantly lower than that of patients without thoracic complications $(p=0.000)$. In particular, the thoracic complication rate was higher in patients with CVA of $40^{\circ}-45^{\circ}(60.0 \%$, 
9/15); however, the complication rate decreased to $25 \%(8 / 32)$ in patients with CVA of $46^{\circ}-$ $51^{\circ}$. Thoracic complications were not observed in patients with CVA of $>51^{\circ}(0.0 \%, 0 / 42)$. We think that as CVA increases, the $12^{\text {th }}$ rib and diaphragm are elevated. This elevation brings the costal and diaphragmatic pleura closer, causing the costodiaphragmatic recess to close. Therefore, we considered that the incidence of thoracic complications was reduced with increased CVA.

Patients who had upper pole and midpolar stone locations had significantly higher thoracic complications than those with other stone locations $(p=0.002)$. Studies have shown that the percutaneous access site rises as the stone localization increases and that stone localization is effective in determining the percutaneous access site. ${ }^{11,19,22}$ Therefore, we think that this situation causes the percutaneous access site to rise and consequently explains why the thoracic complication rates in our study are higher in stones with upper and middle pole locations.

Studies have shown significant difference in age, BMI, and laterality among those with and without thoracic complications after PCNL. ${ }^{11,23-25}$ However, this was not true in our study because no significant difference was found between patients with and without thoracic complications in terms of age, sex, BMI, laterality, and stone size. The absence of significant difference in BMI is thought to be due to the low BMI variability in our study, so we feel that higher BMI variability would have uncovered an association between BMI and thoracic complications.

Moreover, no association was found with renal puncture site between patients with and without thoracic complications $(\mathrm{p}>0.05)$. Similar conclusions were also made by Singh et al., who did not find a significant difference between the groups in terms of thoracic complications in 94 patients who were grouped by upper calix and lower calix entry points. ${ }^{18}$ With regard to the development of thoracic complications, it is not important where the renal parenchyma is punctured from, but where the access was established to the skin and subcutaneous tissue up to the kidney are important.

The ideal puncture has been described as one that provides the shortest and straightest access to all calculi; avoids major vessels, bowels, and lung; lies along the axis of the calyx; and causes minimal parenchymal damage. ${ }^{20}$ However, the ideal puncture should be in a straight line traversing the shortest distance from the skin to the infundibulum. Thus, it is important to identify conditions that will prevent complications as well as ideal puncture conditions. In most cases, we plan to reach the stone with a subcostal access preoperatively as described above, but in some cases, we had to perform supracostal access because the planned route could not be used intraoperatively due to the patient's body structure or kidney movements.

In this study, PCNL was performed under fluoroscopy guidance. Studies have reported that the incidence of adjacent organ injury in ultrasound-guided PCNL is less than that in fluoroscopy-guided PCNL. ${ }^{26,27} \mathrm{Li}$ et al reported that $0.19 \%$ of 8025 patients who underwent ultrasound-guided PCNL with subcostal access had a pleural injury. ${ }^{28}$ In addition, $\mathrm{Ng}$ et al. reported that 72 patients who underwent ultrasound-guided PCNL with subcostal access had no pleural injury. ${ }^{26}$ This condition is thought to be mainly due to the ability of ultrasound to 
provide information about the surrounding viscera and the depth of puncture needle penetration. Therefore, to prevent thoracic complications, especially in patients with narrow CVA, ultrasound-guided PCNL with subcostal access may be a more appropriate and a better choice than PCNL with supracostal access under fluoroscopy.

At present, similar to other surgeries, certain nomograms have important roles in predicting complications and surgical success after PCNL. These nomograms allow the surgeon to define possible postoperative and preoperative complications, as well as the surgical success, and enable them to share these opinions with their patients..$^{9,16,29}$ Based on this, we considered the question, "Can we predict thoracic complications that may develop during surgery by measuring CVA from preoperative CXR of patients before PCNL?" As a result of the CHAID analysis, CVA was shown to have the greatest effect on complication development. According to the model, as the CVA increases, the risk of thoracic complications decreases. Cases with CVA of $>51^{\circ}$ had no risk of complications. Based on these results, we consider that we may predict possible thoracic complications with $10.1 \%$ risk and $89.9 \%$ confidence by evaluating preoperative CVA of patients.

This study had several limitations. This was not a randomized, prospective study but a retrospective analysis of 89 patients who underwent PCNL with supracostal access. To the best of our knowledge, there is no information on the relationship between CVA and thoracic complications in PCNL. Therefore, one of the strengths of this study is that it shows that possible thoracic complications can be predicted by evaluating preoperative CVA. The limitations discussed above can be eliminated by conducting multicenter prospective studies with a larger number of patients in the future, and nomograms can be created to predict the risk of thoracic complications.

\section{Conclusions}

The results showed that preoperative CVA measured using CXR, and supracostal puncture localization is an important indicator for predicting the risk of thoracic complications in PCNL. In particular, $\mathrm{CVA}<51^{\circ}$ in cases with supracostal access is a warning sign for thoracic complications in prone PCNL. Although this study was retrospective and was conducted at a single center, the evidence suggests that we should be watchful of thoracic complications in this patient group; thus, postoperative evaluation for thoracic complications should be made mandatory. 


\section{References}

1. Assimos D, Krambeck A, Miller NL, et al. Surgical management of stones: American urological association/endourological society guideline. Part-II. J Urol 2016;196:1153-69. https://doi.org/10.1016/j.juro.2016.05.091

2. Türk C, Petř́k A, Sarica K, et al. EAU guidelines on interventional treatment for urolithiasis. Eur Urol 2016;69:475-82. https://doi.org/10.1016/j.eururo.2015.07.041

3. Taylor E, Miller J, Chi T, et al. Complications associated with percutaneous nephrolithotomy. Transl Androl Urol 2012;1:223-8. https://doi.org/10.3978/j.issn.2223-4683.2012.12.01

4. Michel MS, Trojan L, Rassweiler JJ. Complications in percutaneous nephrolithotomy. Eur Urol 2007;51:899-906; discussion 906. https://doi.org/10.1016/j.eururo.2006.10.020

5. Shaban A, Kodera A, El Ghoneimy MN, et al. Safety and efficacy of supracostal access in percutaneous renal surgery. $J$ Endourol 2008;22:29-34. https://doi.org/10.1089/end.2007.0054

6. Kekre NS, Gopalakrishnan GG, Gupta GG, et al. Supracostal approach in percutaneous nephrolithotomy: experience with 102 cases. J Endourol 2001 Oct;15:789-91. https://doi.org/10.1089/089277901753205753

7. Yadav R, Aron M, Gupta NP, et al. Safety of supracostal punctures for percutaneous renal surgery. Int J Urol 2006;13:1267-70. https://doi.org/10.1111/j.14422042.2006.01537.x

8. Bjurlin MA, O'Grady T, Kim R, et al. Is routine postoperative chest radiography needed after percutaneous nephrolithotomy? Urology 2012;79:791-5. https://doi.org/10.1016/j.urology.2011.08.053

9. Labadie K, Okhunov Z, Akhavein A, et al. Evaluation and comparison of urolithiasis scoring systems used in percutaneous kidney stone surgery. J Urol 2015;193:154-9. https://doi.org/10.1016/j.juro.2014.07.104

10. Munver R, Delvecchio FC, Newman GE, et al. Critical analysis of supracostal access for percutaneous renal surgery. J Urol 2001;166:1242-6.

11. Sharma K, Sankhwar SN, Singh V, et al. Evaluation of factors predicting clinical pleural injury during percutaneous nephrolithotomy: a prospective study. Urolithiasis 2016 Jun;44:263-70. https://doi.org/10.1007/s00240-015-0820-2

12. Sourial MW, Francois N, Box GN, et al. Supracostal access tubeless percutaneous nephrolithotomy: minimizing complications. World J Urol 2019 Jul;37:1429-33. https://doi.org/10.1007/s00345-018-2518-x

13. MacDuff A, Arnold A, Har J. BTS Pleural disease guideline group. Management of spontaneous pneumothorax: British thoracic society pleural disease guideline. Thorax 2010 Aug;65;Suppl 2:ii18-31. https://doi.org/10.1136/thx.2010.136986

14. Ogan K, Corwin TS, Smith T, et al. Sensitivity of chest fluoroscopy compared with chest CT and chest radiography for diagnosing hydropneumothorax in association with percutaneous nephrostolithotomy. Urology 2003;62:988-92. https://doi.org/10.1016/j.urology.2003.07.024

15. Tepeler A, Armağan A, Akman T, et al. Impact of percutaneous renal access technique on outcomes of percutaneous nephrolithotomy. J Endourol 2012;26:828-33. https://doi.org/10.1089/end.2011.0563 
16. Kumsar Ş, Aydemir H, Halis F, et al. Value of preoperative stone scoring systems in predicting the results of percutaneous nephrolithotomy. Cent Eur J Urol 2015;68:3537. https://doi.org/10.5173/ceju.2015.552

17. Sofer M, Druckman I, Blachar A, et al. Noncontrast computed tomography after percutaneous nephrolithotomy: findings and clinical significance. Urology 2012;79:1004-10. https://doi.org/10.1016/j.urology.2011.11.022

18. Singh R, Kankalia SP, Sabale V, et al. Comparative evaluation of upper versus lower calyceal approach in percutaneous nephrolithotomy for managing complex renal calculi. Urol Ann Jan-Mar 2015;7:31-5. https://doi.org/10.4103/0974-7796.148591

19. Lojanapiwat B, Prasopsuk S. Upper-pole access for percutaneous nephrolithotomy: comparison of supracostal and infracostal approaches. J Endourol 2006;20:491-4. https://doi.org/10.1089/end.2006.20.491

20. Sinha M, Krishnappa P, Subudhi SK, et al. Supracostal percutaneous nephrolithotomy: A prospective comparative study. Indian J Urol 2016 Jan-Mar;32:45-9. https://doi.org/10.4103/0970-1591.173121

21. Narasimham DL, Jacobsson B, Vijayan P, et al. Percutaneous nephrolithotomy through an intercostal approach. Acta Radiol 1991 Mar;32:162-5.

22. Özgör F, Küçüktopcu O, Şimşek A, et al. Percutaneous nephrolithotomy for isolated calyceal stones: how important is the stone location? Turk J Urol 2015;41:171-6. https://doi.org/10.5152/tud.2015.06787

23. Bruhn A, Hyams E, Shah O. Percutaneous nephrolithotomy in obese patients: could obesity be protective for access? J Urol 2010;183:e610. https://doi.org/10.1016/j.juro.2010.02.1346

24. Palnizky G, Halachmi S, Barak M. Pulmonary complications following percutaneous nephrolithotomy: a prospective study. Curr Urol 2013;7:113-6. https://doi.org/10.1159/000356260

25. Okeke Z, Smith AD, Labate G, et al. Prospective comparison of outcomes of percutaneous nephrolithotomy in elderly patients versus younger patients. $J$ Endourol 2012;26:996-1001. https://doi.org/10.1089/end.2012.0046

26. Ng FC, Yam WL, Lim TYB, et al. Ultrasound-guided percutaneous nephrolithotomy: advantages and limitations. Investig Clin Urol 2017;58(5):346-52. https://doi.org/10.4111/icu.2017.58.5.346

27. Lojanapiwa B. The ideal puncture approach for PCNL: Fluoroscopy, ultrasound or endoscopy? Indian J Urol 2013;3:208-13. https://doi.org/10.4103/0970-1591.117284

28. Li J, Xiao B, Hu W, et al. Complication and safety of ultrasound guided percutaneous nephrolithotomy in 8,025 cases in China. Chin Med J 2014;127(24):4184-9.

29. Smith A, Averch TD, Shahrour K, et al. A nephrolithometric nomogram to predict treatment success of percutaneous nephrolithotomy. J Urol 2013;190:149-56. https://doi.org/10.1016/j.juro.2013.01.047 


\section{Figures and Tables}

Fig. 1. The costovertebral angle, defined as the angle between the $12^{\text {th }}$ rib and vertebrae.

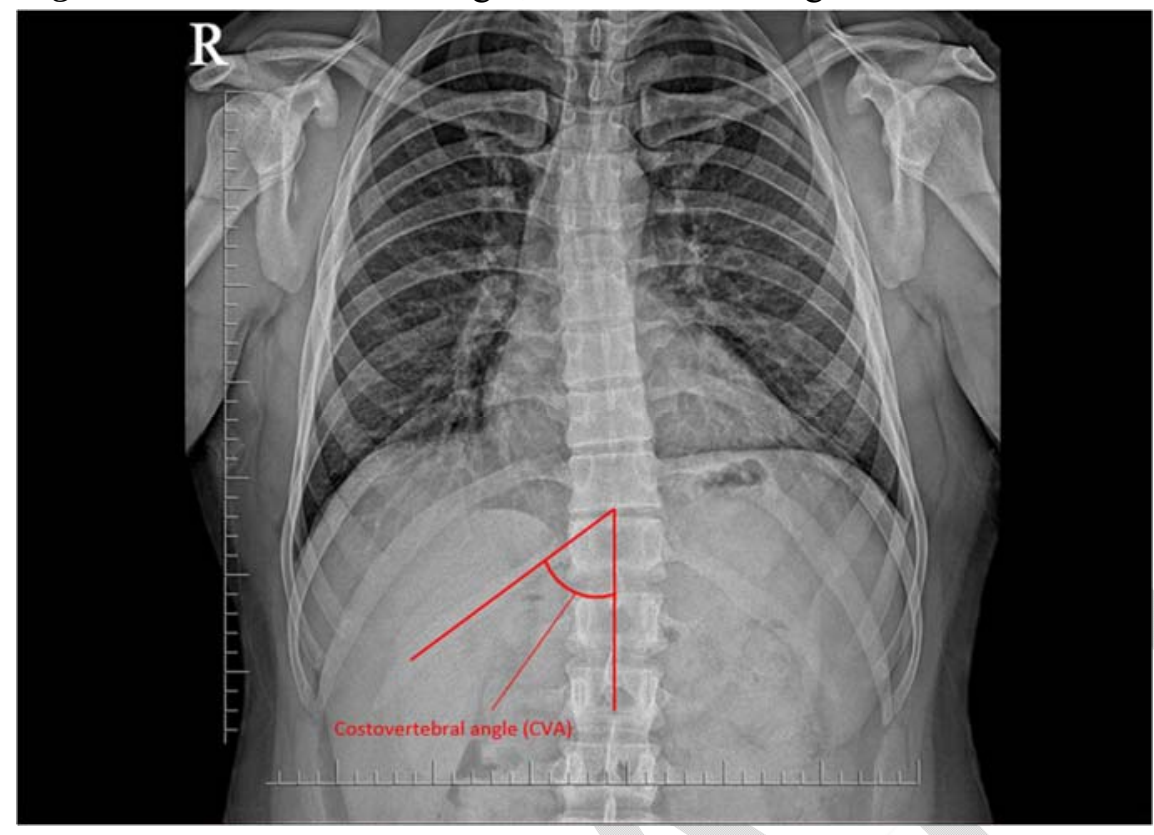

Fig. 2. CHAID analysis (decision tree method), which enables the determination of the effect level of variables on the development of complications.

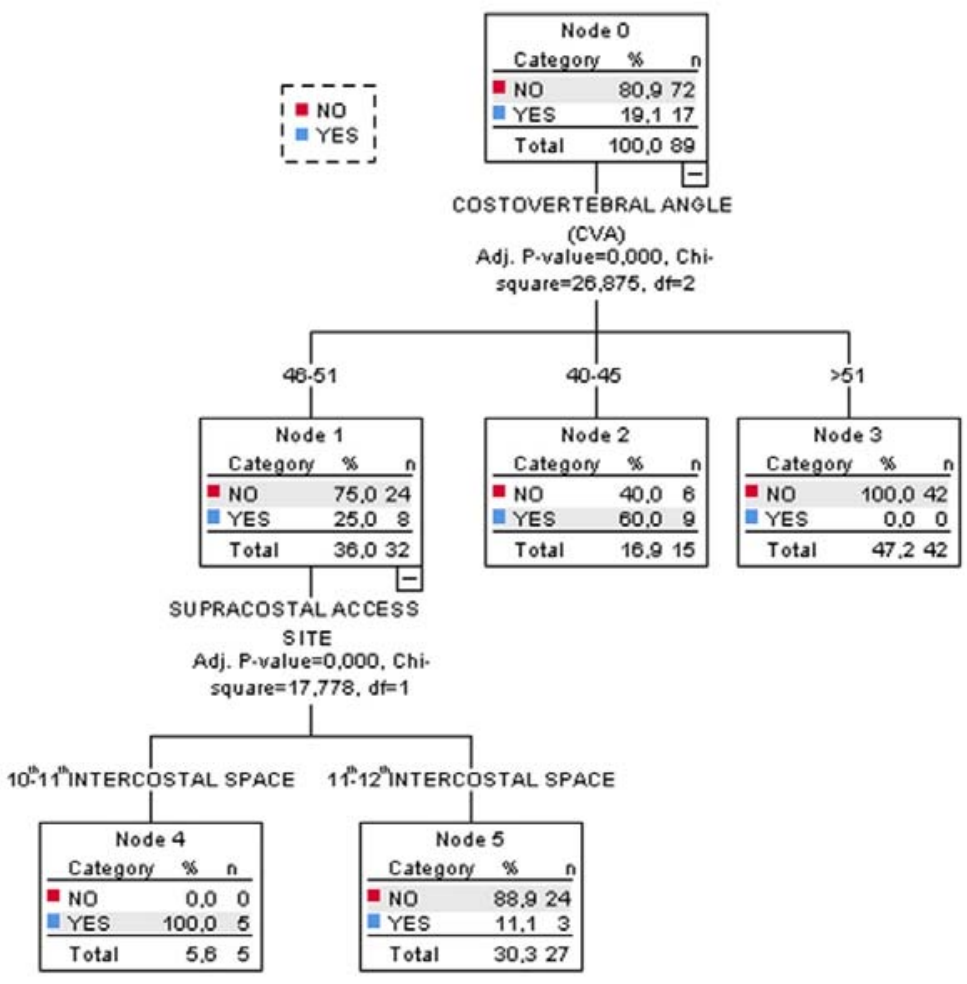




\begin{tabular}{|c|c|}
\hline \multicolumn{2}{|l|}{ Characteristic } \\
\hline Age (years), mean $\pm \mathrm{SD}$ & $46.12 \pm 15.66$ \\
\hline \multicolumn{2}{|l|}{ Sex, $n(\%)$} \\
\hline Female & $30(33.7)$ \\
\hline Male & $59(66.3)$ \\
\hline Body mass index $\left(\mathrm{kg} / \mathrm{m}^{2}\right)$, mean $\pm \mathrm{SD}$ & $26.68 \pm 4.95$ \\
\hline \multicolumn{2}{|l|}{ Laterality, $\mathrm{n}(\%)$} \\
\hline Right & $50(56.2)$ \\
\hline Left & $39(43.8)$ \\
\hline Thoracic complications, Yes/No, n (\%) & $17(19.1) / 72(80.9)$ \\
\hline \multicolumn{2}{|l|}{ Costovertebral angle (degree), mean $\pm \mathrm{SD}$} \\
\hline With thoracic complications & $45.47 \pm 3.59$ \\
\hline Without thoracic complications & $53.26 \pm 5.98$ \\
\hline Stone characteristics, $\mathrm{n}(\%)$ & 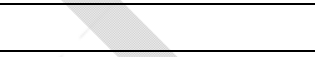 \\
\hline Staghorn & $7(7.9)$ \\
\hline Multiple/pelvic/single calyceal & $82(92.1)$ \\
\hline Mean stone surface area $\left(\mathrm{mm}^{2}\right)$, mean $\pm \mathrm{SD}$ & $510.49 \pm 433.85$ \\
\hline
\end{tabular}

SD: standard deviation. 


\begin{tabular}{|c|c|c|c|}
\hline & \multicolumn{3}{|c|}{ Thoracic complications } \\
\hline & $\begin{array}{l}\text { With thoracic } \\
\text { complications } \\
(n=17)\end{array}$ & $\begin{array}{c}\text { Without thoracic } \\
\text { complications } \\
(n=72)\end{array}$ & $\mathbf{p}$ \\
\hline Laterality (\%) & & & $\begin{array}{c}\chi^{2}=0.060, \mathrm{df}=1 \\
\mathrm{p}=0.807\end{array}$ \\
\hline Right & $10(20.0)$ & $40(80.0)$ & \\
\hline Left & $7(17.9)$ & $32(82.1)$ & \\
\hline Stone location (\%) & & & $\begin{array}{c}\chi^{2}=14.782, \mathrm{df}=3 \\
\mathrm{p}=0.002\end{array}$ \\
\hline Upper pole & $7(46.7)$ & $8(53.3)$ & \\
\hline Midpolar & $3(50.0)$ & $3(50.0)$ & \\
\hline Lower pole & $1(5.9)$ & $16(94.1)$ & \\
\hline Kidney pelvis & $6(11.8)$ & $45(88.2)$ & \\
\hline Renal puncture site $(\%)$ & & & $\begin{array}{c}\chi^{2}=6.403, \mathrm{df}=3 \\
\mathrm{p}=0.094\end{array}$ \\
\hline Upper calyx & $5(13.5)$ & $32(86.5)$ & \\
\hline Midpolar calyx & $8(19.5)$ & $33(80.5)$ & - \\
\hline Lower calyx & $4(50.0)$ & $4(50.0)$ & \\
\hline Posterior calyx & $0(0.0)$ & $3(100.0)$ & \\
\hline Supracostal access site $(\%)$ & & & $\begin{array}{c}\chi^{2}=10.892, d f=2 \\
p=0004\end{array}$ \\
\hline $11^{\text {th }}-12^{\text {th }}$ intercostal space & $11(14.1)$ & $67(85.9)$ & \\
\hline $10^{\text {th }}-11^{\text {th }}$ intercostal space & $6(54.5)$ & $5(45.5)$ & \\
\hline Costovertebral angle (\%) & & & $\begin{array}{c}\chi^{2}=26.875, \mathrm{df}=2, \\
p=0.000\end{array}$ \\
\hline $40^{\circ}-45^{\circ}$ & $9(60.0)$ & $6(40.0)$ & \\
\hline 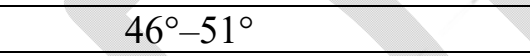 & $8(25.0)$ & $24(75.0)$ & \\
\hline$>51^{\circ}$ & $0(0.0)$ & $42(100.0)$ & \\
\hline $\begin{array}{l}\text { Mean stone surface area }\left(\mathrm{mm}^{2}\right) \\
\text { mean } \pm \text { SD }\end{array}$ & $629.02 \pm 594.00$ & $482.50 \pm 386.90$ & $\mathrm{p}=0.213$ \\
\hline Age & $46.12 \pm 16.30$ & $46.12 \pm 15.63$ & $\begin{array}{c}\chi^{2}=8.347, \mathrm{df}=7 \\
\mathrm{p}=0.303\end{array}$ \\
\hline Sex & & & $\begin{array}{c}\chi^{2}=0.974, \mathrm{df}=1 \\
\mathrm{p}=0.324\end{array}$ \\
\hline Female & $4(13.3)$ & $26(86.7)$ & \\
\hline Male & $13(22.0)$ & $46(78)$ & \\
\hline $\begin{array}{l}\text { Body mass index }\left(\mathrm{kg} / \mathrm{m}^{2}\right) \\
\text { mean } \pm \mathrm{SD}\end{array}$ & $26.99 \pm 4.87$ & $25.35 \pm 5.24$ & $\begin{array}{c}\chi^{2}=1.712, d f=3 \\
p=0.634\end{array}$ \\
\hline
\end{tabular}

SD: standard deviation. 